\title{
ALBERTA ARBITRATION AND MEDIATION SOCIETY
}

\section{PETER PORTLOCK}

The Alberta Arbitration and Mediation Society is a not-for-profit organization which provides education and information to its members and the general public on solving disputes more effectively. The Society has been in existence since 1982 and has over 450 members (over half of whom are lawyers) engaged in the practice of arbitration and mediation throughout the province. Membership in the Society - which is open to anyone interested in alternative dispute resolution - has doubled in the past eighteen months, a reflection of the interest in ADR processes and the many opportunities for applying them in new situations - schools, hospitals, amateur sport, neighbourhood disputes and consumer complaints, to name just a few.

The Alberta Arbitration and Mediation Society is currently the largest and most vigorous provincial affiliate of the Arbitration and Mediation Institute of Canada, Inc., and retains jurisdictional responsibility for recommending candidates to the national organization for the designations, "Chartered Arbitrator" and "Chartered Mediator."

The Society's main function is to provide training in arbitration, mediation, negotiation and conflict resolution skills, which it does through regularly-scheduled year-round courses in Edmonton and Calgary (and other centres when there is sufficient demand). The Society's newest initiative is a "Certificate Program in Conflict Management," currently offered through Grant MacEwan Community College in Edmonton and the University of Calgary's Faculty of Continuing Education.

The Society also produces an annual "Directory of Arbitrators and Mediators," available without charge to anyone on request. Wide distribution of this directory throughout the public and private sectors ensures that it remains an effective referral tool. Practitioners are listed in the Directory according to their field of specialty; each listing also contains a brief resumé. The Society provides a mediator/arbitrator telephone referral service through its 1-800 line, and maintains a large and up-to-date resource centre with print and audio-visual material on all aspects of ADR, which is available on loan to the public. Finally, we offer monthly "continuing education" meetings, usually at lunch time, in Edmonton and Calgary, featuring topics of current interest to members, practitioners and friends of ADR.

Most recently, the Society, through its member practitioners, has become involved in providing a consultative service on dispute resolution systems design, and in assisting not-for-profit societies in resolving internal disputes for which no other recourse is available through the Corporate Registry. The Society's wholly-owned subsidiary, "Alberta Arbitration and Mediation Services, Inc." functions as the Provincial Administrator for the Canadian Motor Vehicle Arbitration Plan, and provides ADR administration services for the community at large. 
The Society has produced "Rules for Arbitration" and "The Arbitrator's Handbook," in addition to course training syllabi for each of its fifteen conflict resolution courses. We have also created Codes of Ethical Conduct for arbitrators and mediators, and "Points to Consider When Choosing an Arbitrator or Mediator"; these publications are incorporated within the "Directory" mentioned previously.

The Society, which is based in Edmonton, has relocated its offices to the John V. Decore Centre for Dispute Resolution at the University of Alberta, Faculty of Law, and will be responsible for the management of the Centre, including the booking of facilities for arbitration hearings and mediations.

We look forward to our association with the Decore Centre and the University, and welcome any inquiries on any aspect of the Society's operations. 